OPEN ACCESS

Edited by:

Hongxing Zhang

Xuzhou Medical University, China

Reviewed by:

Yimin Hu,

Second Affiliated Changzhou People's Hospital of Nanjing Medical

University, China

Martin K. Church,

Charité - Universitätsmedizin

Berlin, Germany

*Correspondence:

Jie $\mathrm{Li}$

xylijie@csu.edu.cn

Jianglin Zhang

leozil1010@126.com

Minxue Shen

shenmx1988@csu.edu.cn

†These authors have contributed equally to this work

Specialty section

This article was submitted to Mood and Anxiety Disorders,

a section of the journal

Frontiers in Psychiatry

Received: 19 January 2021

Accepted: 28 July 2021

Published: 07 September 2021

Citation:

Huang Y, Xiao Y, Jing D, Li J, Zhang J,

Chen $X$ and Shen $M(2021)$ Association of Chronic Spontaneous Urticaria With Anxiety and Depression in Adolescents: A Mediation Analysis.

Front. Psychiatry 12:655802.

doi: 10.3389/fpsyt.2021.655802

\section{Association of Chronic Spontaneous Urticaria With Anxiety and Depression in Adolescents: A Mediation Analysis}

\author{
Yuzhou Huang ${ }^{1,2,3,4 \dagger}$, Yi Xiao ${ }^{1,2,3,44}$, Danrong Jing ${ }^{1,2,3,4}$, Jie $\mathrm{Li}^{1,2,3,4 *}$, Jianglin Zhang ${ }^{5 *}$, \\ Xiang Chen ${ }^{1,2,3,4}$ and Minxue Shen ${ }^{6 *}$ \\ ${ }^{1}$ Department of Dermatology, Xiangya Hospital, Central South University, Changsha, China, ${ }^{2}$ National Clinical Research \\ Center for Geriatric Disorders (Xiangya Hospital), Changsha, China, ${ }^{3}$ Hunan Engineering Research Center of Skin Health and \\ Disease, Changsha, China, ${ }^{4}$ Hunan Key Laboratory of Skin Cancer and Psoriasis, Changsha, China, ${ }^{5}$ Department of \\ Detmatology, Shenzhen People's Hospital, The Second Clinical Medical College, Jinan University, The First Affiliated Hospital, \\ Southern University of Science and Technology, Shenzhen, China, ${ }^{6}$ Department of Social Medicine and Health Management, \\ Xiangya School of Public Health, Central South University, Changsha, China
}

Background: Chronic spontaneous urticaria (CSU) is related to psychiatric comorbidities. It is not clear whether the relationship is affected by modifiable factors.

Objectives: To investigate whether the effect of CSU on anxiety and depression in adolescents is mediated by the symptoms of itching and sleep disturbance.

Methods: Questionnaire survey was conducted among newly enrolled college students. Dermatologists diagnose skin diseases, including CSU, during health examination. Anxiety and depression were measured by the Generalized Anxiety Disorder Scale and Patient Health Questionnaire, respectively. Sleep quality was measured by the Pittsburgh Sleep Quality Index. The symptoms of itching were measured by the numeric rating scale. According to the hypothesis, the mediating effect model was put forward and the structural equation model is used to build the mediation effect model. The mediation effect model was proposed according to the hypothesis and established using a structural equation model.

Results: A total of 2,358 students with no history of systemic disease and no pruritus disease (except CSU) were included in the analysis. A total of 393 CSU patients were included, and 1,965 healthy controls were selected based on age and sex matching. CSU was significantly associated with both anxiety and depression when the symptoms of itching and sleep quality were not modeled. A mediation model was proposed as $\mathrm{CSU} \rightarrow$ itching $\rightarrow$ sleep disturbance $\rightarrow$ anxiety or depression. Itching and sleep quality mediated 65.4 and $77.6 \%$ of CSU's effects on anxiety and depression, respectively, and CSU had no significant direct effect on anxiety or depression in the mediation models.

Conclusions: The associations of CSU with anxiety and depression were mediated by the symptoms of itching and sleep disturbance. Effectively reducing the symptoms of itching thereby could increase natural sleep, which can further treat the emotional disorders among patients with CSU.

Keywords: chronic spontaneous urticaria, itching, sleep disturbance, mediation effect, depression, anxiety 


\section{INTRODUCTION}

Chronic urticaria (CU) is a common skin disease characterized by the occurrence of wheals (hives), angioedema, or both lasting more than 6 weeks (1). CU can be classified into chronic spontaneous urticaria (CSU) and inducible urticaria (IU) (13). CSU occurs spontaneously with no obvious cause, while IU occurs when the formation of hives is reproducible after specific stimulus (4). CU affects $0.5-1 \%$ of the general population (5) and $0.1-0.3 \%$ of children (6). However, the prevalence of CU in adolescents is underappreciated. Globally, urticaria contributes to 4.7 million age-standardized disability-adjusted life years and 4.7 years lived with disability (7). Many studies have shown that patients with CSU often experience mental complications (8-10). The most common mental disorders observed in CSU patients are depression, anxiety, and somatoform disorders (8). The wide range of estimates of psychosocial factors among patients with CU was 16-96\% (11). A recent meta-analysis found that CSU patients are six times more likely to suffer from anxiety and depression than healthy people (12). So, the psychiatric disorders associated with CSU should be taken seriously.

CSU is characterized by transient itching. Itching symptoms in patients with CSU have been described as stinging, tickling, and burning. Because of unpredictable attacks of pruritus and swelling, urticaria can seriously affect their quality of life (13). Itching is one of the main symptoms and the most important cause of sleep disturbance in patients with CSU. The severity of itching in CSU patients is associated with severe impairment of sleep quality (14-16). CSU severely affects sleep and quality of life, leading to difficulties related to work, family activities, social life, family relationships, sex, hobbies, and holidays.

Previous research has found that itching and sleep disturbance have a significant effect on mental disorders. Most clinical studies have revealed a correlation between mental disorders and chronic pruritus in patients with skin disorders. Chronic itching is associated with a high incidence of stress, anxiety, depression, and even suicidal thoughts, leading to major defects in quality of life (17-21). Sleep disturbance is significantly associated with increased risk of depression (22).

It is unknown whether CSU causes emotional problems through the symptoms of itching and sleep disturbance. Our study aims to investigate the mediation effect of the symptoms of itching and sleep disturbance on emotional problems in adolescents with CSU.

\section{METHODS}

\section{Study Design}

The College Student Skin Health Survey (CSSHS) (23) is a 4year dynamic cohort of college students aiming to investigate skin health, diseases, and risk factors in adolescents. In the current study, we proposed a hypothesized pathway from CSU to emotional problems and tested the hypothesis using the baseline data of the cohort. Students from all over the country were admitted to four universities in four provinces (Hunan, Hubei, Fujian, and Xinjiang) and immediately performed health examinations and questionnaire surveys. All newly enrolled students who agreed to participate were classified as a cluster in September 2017 and September 2018. Participants that reported severe underlying diseases or the use of NSAIDs (24), or were diagnosed as other pruritic skin diseases, were excluded from the statistical analysis. We continuously selected patients with CSU from baseline data and matched healthy controls at a ratio of 1:5 based on age and sex matching.

\section{Questionnaire and Measurements}

During the physical examination, the University Student Affairs Department conducted a web-based questionnaire survey within 1 day. The questionnaire was self-reported (in computer rooms) and the questionnaire took $15 \mathrm{~min}$ to fulfill on average. The questionnaire was comprised of demographic information, history of diseases that might be associated with skin health, history of allergy, cigarette smoking, alcohol drinking, intake of soft drinks, water intake, food taste preference, defecation, sport, sleep quality, anxiety, depression, bath habit, skincare, and sun exposure. Anxiety and depression were measured by the two-item Generalized Anxiety Disorder Scale (GAD-2) and two-item Patient Health Questionnaire (PHQ-2), respectively. Sleep quality was measured by the Pittsburgh Sleep Quality Index (PSQI). The intensity of itching was measured by the numeric rating scale (NRS) of itching. For GAD-2, PHQ-2, PSQI, and NRS of the symptoms of itching, a higher score signified a greater level of anxiety, depression, sleep disturbance, and the symptoms of itching, respectively.

\section{Clinical Evaluation and Diagnosis}

Diagnosis of skin diseases and inquiry of disease history were performed by certified dermatologists during the health examination. Clinical manifestation, disease history, and family history of participants were inquired, and physical examinations were conducted to further diagnose CSU. During the health examination, qualified dermatologists conducted a skin disease diagnosis and medical history inquiry. The doctors asked the participants clinical manifestations, medical history, and family history and performed physical examinations to further diagnose CSU. CSU was diagnosed as wheals (hives), angioedema onset for 6 weeks or more with no obvious cause.

\section{Statistical Analysis}

Continuous data were presented as mean \pm standard deviation, and between-group difference was tested using analysis of variance (ANOVA). Multiple comparisons were performed with the Least Significant Difference (LSD) $t$-test. Categorical data was presented as number (\%), and the between-group difference was tested using the chi-square test.

The mediation effect model was performed to investigate whether CU affect emotional problems through itch and sleep disturbance. We proposed a model with a three-path mediated effect as: CSU (X) $\rightarrow$ itching (M1) $\rightarrow$ sleep disturbance (M2) $\rightarrow$ anxiety or depression (Y). As shown in Figure 1A, the total effect of predictor $\mathrm{X}$ on outcome $\mathrm{Y}$ is $c$; in Figure 1B, the direct effect of $\mathrm{X}$ on $\mathrm{Y}$ is $c^{\prime}$, and the mediation effect of M1 and M2 is calculated as $a 1 \times b 2+b 1 \times a 3+a 1 \times a 2 \times a 3$. The significance of the mediation effect was tested using the Bootstrap method. 

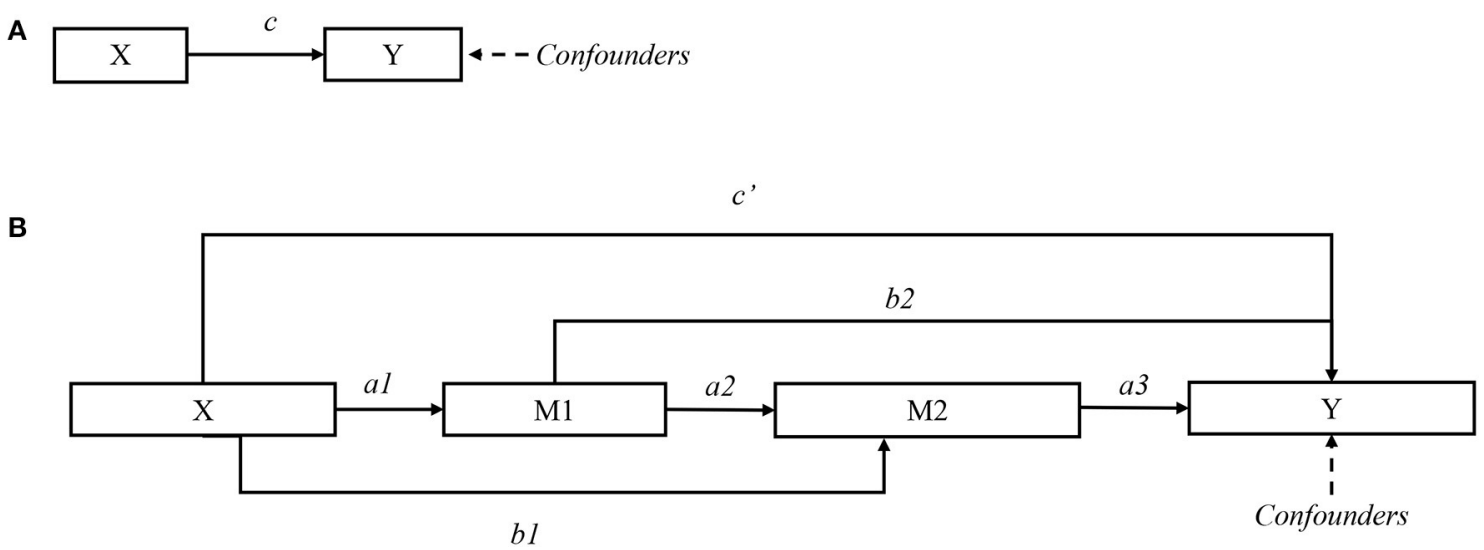

FIGURE 1 | Directed acyclic graph for mediation effect model. (A) Total effect c. (B) Direct effect c'; and mediation effects a1 $\times$ b2, b1 $\times$ a3, and a1 $\times$ a2 $\times$ a3.

TABLE 1 | Characteristics of participants, stratified by chronic spontaneous urticaria.

\begin{tabular}{|c|c|c|c|c|}
\hline \multirow[b]{2}{*}{ Characteristics } & \multirow[b]{2}{*}{ Total } & \multicolumn{2}{|c|}{$\begin{array}{c}\text { Chronic spontaneous } \\
\text { urticaria }\end{array}$} & \multirow[b]{2}{*}{$P$} \\
\hline & & Case & Control & \\
\hline \multicolumn{5}{|l|}{ Geographic region $^{a}$} \\
\hline North & $246(10.4)$ & $38(9.7)$ & 208 (10.6) & 0.198 \\
\hline Northeast & $127(5.4)$ & $21(5.3)$ & $106(5.4)$ & \\
\hline East & $573(24.3)$ & $74(18.8)$ & $499(25.4)$ & \\
\hline Central & $664(28.2)$ & $121(30.8)$ & $543(27.6)$ & \\
\hline South & 217 (9.2) & 45 (11.5) & $172(8.8)$ & \\
\hline Southwest & $302(12.8)$ & 67 (17.0) & 235 (12.0) & \\
\hline Northwest & $229(9.7)$ & $27(6.9)$ & $202(10.3)$ & \\
\hline Age (years) & & $18.3 \pm 0.7$ & $18.3 \pm 0.7$ & 1.0 \\
\hline \multicolumn{5}{|l|}{ Gender } \\
\hline Male & $1,128(47.8)$ & $188(47.8)$ & $940(47.8)$ & 1.0 \\
\hline Female & $1,230(52.2)$ & $205(52.2)$ & $1,025(52.2)$ & \\
\hline \multicolumn{5}{|l|}{ Ethnicity } \\
\hline Han & 2,095 (89.0) & 347 (89.0) & 1,748 (89.0) & 0.704 \\
\hline Other & $263(11.0)$ & $46(11.0)$ & 217 (11.0) & \\
\hline \multicolumn{5}{|c|}{ Annual household income (yuan) } \\
\hline$<10,000$ & $185(7.8)$ & $18(4.6)$ & $167(8.5)$ & 0.001 \\
\hline $10,000-29,999$ & $470(19.9)$ & $63(16.0)$ & $407(20.7)$ & \\
\hline $30,000-49,999$ & 390 (16.5) & $69(17.6)$ & 321 (16.3) & \\
\hline $50,000-99,999$ & $571(24.2)$ & $100(25.4)$ & $471(24.0)$ & \\
\hline $100,000-199,999$ & $529(22.4)$ & $101(25.7)$ & $428(21.8)$ & \\
\hline$\geq 200,000$ & $213(9.0)$ & $42(10.7)$ & $171(8.7)$ & \\
\hline
\end{tabular}

${ }^{a}$ North: Beijing, Tianjin, Hebei, Shanxi, Inner Mongolia; Northeast: Liaoning, Jilin, Heilongjiang; East: Shanghai, Jiangsu, Zhejiang, Anhui, Fujian, Jiangxi, Shandong, Taiwan; Central: Henan, Hubei, Hunan; South: Guangdong, Guangxi, Hainan, Hong Kong, Macao; Southwest: Chongqing, Sichuan, Guizhou, Yunnan, Tibet; Northwest: Shaanxi, Gansu, Qinghai, Ningxia, Xinjiang.

If the direct effect is insignificant and the mediation effect is significant, then mediators have a complete mediation effect on the outcome. $P<0.05$ was considered statistically significant for all tests. Statistical analysis was performed in SPSS software 23.0 (IBM, NY, USA).

\section{RESULTS}

Based on screening of baseline data, we identified a total of 393 CSU patients, and a healthy control group of 1,965 was selected based on age and gender matching. The characteristics of the students stratified by CSU are shown in Table 1. Household income was associated with CSU.

In crude estimation, as shown in Table 2, students with CSU had significantly higher levels of the symptoms of itching, sleep disturbance, anxiety, and depression. Results remained consistent when dichotomizing the outcomes by certain cutoffs.

As shown in Figure 2A, CSU had significant total effects on sleep quality and emotional problems after adjustment for geographic region, age, gender, household income, food allergy, and drug allergy. One-mediator model is shown in Figure 2B: the direct effect of CSU on anxiety and depression was not significant; the symptoms of itching mediated 87.1 and $110.0 \%$ of CSU's effect on anxiety and depression, respectively (both $P<0.001)$. The two-mediator model is shown in Figure 2C: the direct effect of CSU on sleep quality, anxiety, and depression was not significant; the symptoms of itching and sleep disturbance mediated 95.7 and $116.7 \%$ of CSU's effect on anxiety and depression, respectively (both $P<0.001$ ). The total effect, direct effect, and mediation effect are summarized in Table 3.

\section{DISCUSSION}

We proposed a mediation model from CSU to the symptoms of itching, sleep disturbance, and finally emotional problems in adolescents. The effects of CSU on anxiety and depression were fully mediated by the symptoms of itching and sleep disturbance, and CSU had no significant direct effect on anxiety or depression.

It is reported that at least $30 \%$ of patients with skin diseases have mental and psychosocial disorders (25-29). A systematic review found that the prevalence of depression in psoriasis 
TABLE 2 | Comparison of itch, sleep quality, anxiety, and depression among adolescents with chronic spontaneous urticaria and those without.

\begin{tabular}{|c|c|c|c|c|c|}
\hline Outcomes & \multicolumn{2}{|c|}{ csu } & \multicolumn{3}{|c|}{ Effect size } \\
\hline Itch NRS $\geq 3$ & $129(32.8)$ & 239 (12.2) & & $3.53(2.75-4.53)$ & $<0.001$ \\
\hline PSQI & $4.20 \pm 3.14$ & $3.54 \pm 2.90$ & $0.67(0.35-0.99)$ & & $<0.001$ \\
\hline$P S Q I \geq 6$ & $120(30.5)$ & 404 (20.6) & & $1.70(1.31-2.16)$ & $<0.001$ \\
\hline GAD-2 $\geq 3$ & $34(8.7)$ & $99(5.0)$ & & 1.79 (1.19-2.68) & 0.005 \\
\hline PHQ-2 & $0.97 \pm 1.27$ & $0.79 \pm 1.14$ & $0.18(0.06-0.31)$ & & 0.005 \\
\hline $\mathrm{PHQ}-2 \geq 3$ & $34(8.7)$ & 109 (5.5) & & $1.61(1.08-2.41)$ & 0.020 \\
\hline
\end{tabular}

CSU, chronic spontaneous urticaria; OR, odds ratio; Cl, confidence interval; NRS, numeric rating scale; GAD, Generalized Anxiety Disorder; PHQ, Patient Health Questionnaire; PSQI, Pittsburgh sleep quality index; NRS, numeric rating scale.

patients ranged from 9 to $62 \%$, and the prevalence of anxiety ranged from 11 to $43 \%$ (30). A recent study showed that depression, anxiety, and suicidal ideation are more common among patients with atopic dermatitis (31). The impact of CSU on quality of life was similar to that of cardiovascular disease (32). A systematic review showed that psychosocial factors had a prevalence of $46 \%$ in CSU patients (11). Our research is consistent with previous research results. The risk of anxiety and depression in urticaria patients is 1.79 times and 1.61 times that of normal people, respectively.

It is mentioned in "the European S2k Guideline on Chronic Pruritus" that all patients with urticaria have itching (33). It has also been reported that CSU is the source of itching in about $3 \%$ of children (34). A recent multicenter study found that compared with patients without itching, the depression and suicidal ideation of patients with skin diseases were strongly correlated with the presence of itching (35). This shows that the mental health problems of patients with skin diseases are largely related to itching. Other studies have confirmed this (36). One presumed reason for this correlation is that itching is associated with skin inflammation, which induces serotonin networks in the brain, leading to depression and anxiety $(37,38)$. Therefore, the symptoms of itching can be used as a major cause of mediating the occurrence of anxiety and depression in patients with CSU.

CSU has been reported to be associated with sleep disorders. Previous studies showed that patients with longer duration of CSU reported more sleep disturbance, tiredness, and irritability (39). Caine found that comparison of the Nottingham Health Profile scores shows that sleep disruption was a bigger problem for patients with CU. O'Donnell et al. reported that $38 \%$ of $\mathrm{CU}$ patients reported marked sleep disruption, and another $54 \%$ had sleep interference (40). A study in Singapore showed that many patients had difficulty falling asleep and often woke in the night (14). The CU-Q2oL scores from the German population showed that the greatest burdens of QoL were sleep, itching/embarrassment, and mental status (41).

Longitudinal studies have shown that subjective sleep disturbance is the main risk factor for the first-onset and recurrent depressive episodes of young and old people in the future $(22,42-44)$. Poor sleep quality can produce negative cognitions and emotions that are not conducive to sleep, such as anxiety and anger. As these vicious cycles continue, the risk of depression increases (45). One study showed that people with persistent insomnia have an average increased risk of depression by 3.7 times compared with those without insomnia (46). A meta-analysis found that people with insomnia have twice the risk of depression compared to people without sleep disorders (22). A systematic study of the relationship between adolescents' sleep duration and emotions found that sleep duration has a significant negative impact on the various emotional states of healthy adolescents (47). In a recent meta-analysis, it was found that lack of sleep may bring the risk of anxiety-related symptoms (48). Classic H1-antihistamines increase daytime sleepiness and reduce sleep quality scores, which have a negative impact on mood. The second-generation antihistamines have little effect on mood and are better than H1-antihistamines (49). Therefore, we believe that increasing sleep quality and natural sleep are more beneficial for anxiety and depression in patients with urticaria.

According to previous studies, the relationship between CSU and sleep disorders and the relationship between sleep disorders and anxiety and depression have been found. We can speculate that sleep disorder is a mediator of anxiety and depression in CSU patients.

In our study, when modeling itching as the only mediator, it mediated 87.1 and $110.0 \%$ of CSU's effect on anxiety and depression, respectively. By contrast, when modeling itching as the first and sleep quality as the second mediator, they mediated 95.7 and $116.7 \%$ of CSU's effect on anxiety and depression, respectively. The two-mediator model explained significantly greater variations than the one-mediator model. This is a further evidence of the importance of sleep disorders in CSU-associated emotional problems.

The study has limitations. First, the study was a casecontrol study, and the level of evidence limits the capability of causal relationship inference. Longitudinal observations are needed to confirm this proposed mediation model. Second, the study population was limited to highly homogeneous adolescents aged around 18 and having a similar educational background. The generalizability of the findings might be limited to other populations. Third, owing to the feasibility of study 


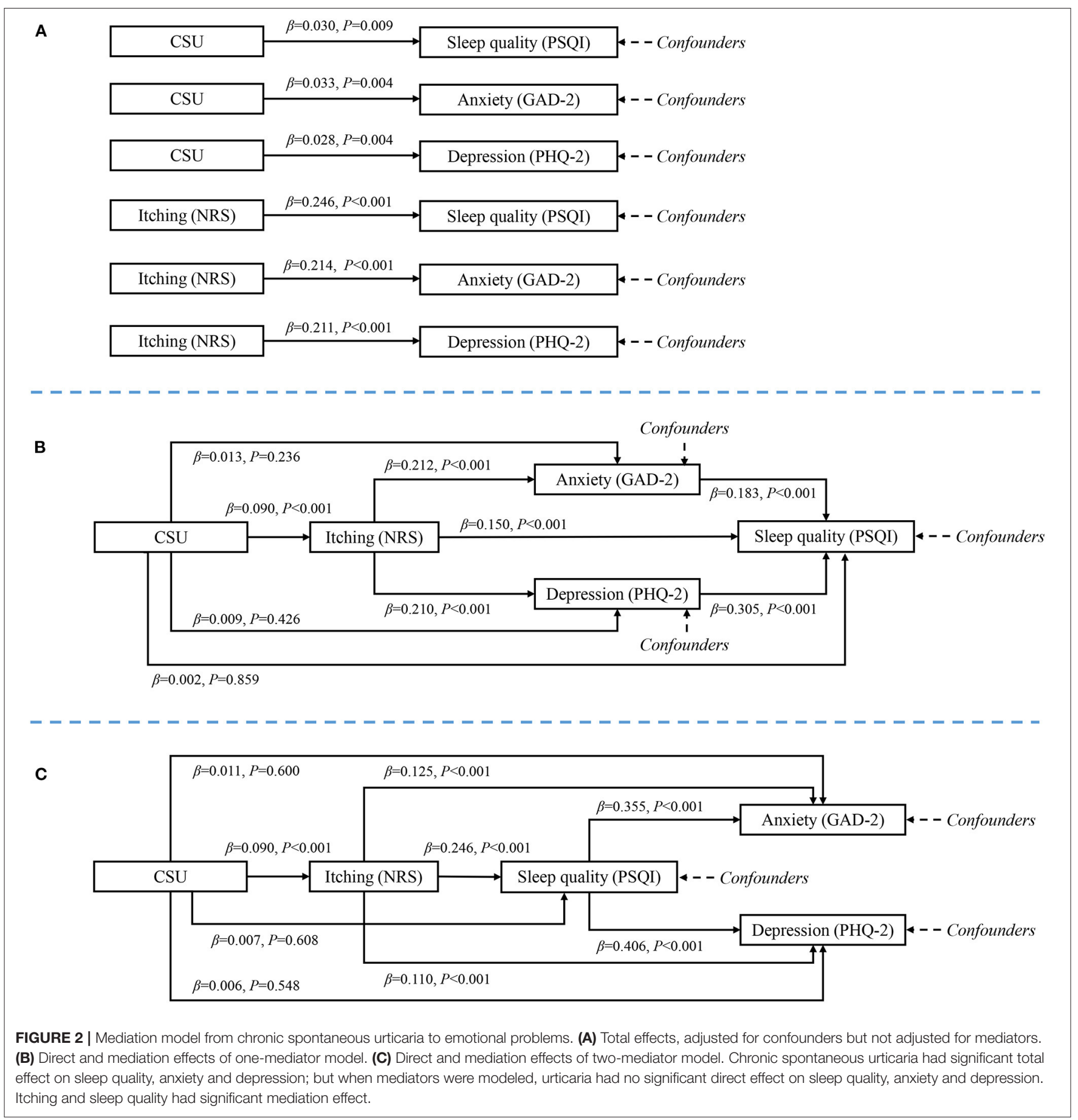

implementation, anxiety and depression were only measured by two brief tools that were generally applied in clinical settings. Fourth, the urticaria activity score (UAS) scale and treatment status were not included in the CSU patients' inquiries, which may have a certain influence on the results.

The study also has strengths. First, this was a populationbased epidemiologic survey among adolescents, and it had a higher level of evidence than the hospital-based studies.
Second, the mediation model from CSU to the symptoms of itching, sleep disturbance, and emotional problems was clinically rational; the findings might provide potentially effective methods of an intervention targeting on the mediators. Third, the questionnaire survey and diagnosis for CSU were conducted using standardized methodologies.

In summary, we proposed a mediation effect model to test whether CSU was associated to anxiety and depression 
TABLE 3 | Effect of predictors and mediators for sleep quality, anxiety, and depression.

\begin{tabular}{|c|c|c|c|c|c|c|c|c|c|}
\hline \multirow[b]{2}{*}{ Predictor $(\mathrm{X})$} & \multirow[b]{2}{*}{ Mediator (M) } & \multirow[b]{2}{*}{ Outcome (Y) } & \multicolumn{2}{|c|}{ Total effect ${ }^{a}$} & \multicolumn{2}{|c|}{ Direct effect ${ }^{b}$} & \multicolumn{3}{|c|}{ Mediation effect ${ }^{c}$} \\
\hline & & & Size $^{d}$ & $P$ & Size $^{d}$ & $P$ & Size $(95 \% \mathrm{Cl})^{d}$ & $P$ & $\%$ \\
\hline Itching & Sleep quality & Anxiety & 0.238 & $<0.001$ & 0.123 & $<0.001$ & $0.113(0.098,0.128)$ & $<0.001$ & 47.5 \\
\hline Itching & Sleep quality & Depression & 0.252 & $<0.001$ & 0.143 & $<0.001$ & $0.110(0.095,0.125)$ & $<0.001$ & 43.7 \\
\hline Itching & Anxiety & Sleep quality & 0.271 & $<0.001$ & 0.168 & $<0.001$ & $0.098(0.055,0.141)$ & $<0.001$ & 36.2 \\
\hline Itching & Depression & Sleep quality & 0.271 & $<0.001$ & 0.164 & $<0.001$ & $0.103(0.058,0.148)$ & $<0.001$ & 38.0 \\
\hline CSU & Itching & Sleep quality & 0.084 & $<0.001$ & 0.015 & 0.458 & $0.069(-0.067,0.205)$ & $<0.001$ & 82.1 \\
\hline CSU & Itching & Anxiety & 0.070 & 0.001 & 0.010 & 0.644 & $0.061(0.005,0.117)$ & $<0.001$ & 87.1 \\
\hline CSU & Itching & Depression & 0.060 & 0.004 & -0.005 & 0.818 & $0.066(0.005,0.0 .127)$ & $<0.001$ & 110.0 \\
\hline CSU & Itching $\rightarrow$ sleep quality & Anxiety & 0.070 & 0.001 & 0.003 & 0.870 & $0.067(-0.008,0.142)$ & $<0.001$ & 95.7 \\
\hline CSU & Itching $\rightarrow$ sleep quality & Depression & 0.060 & 0.004 & -0.011 & 0.558 & $0.070(-0.007,0.147)$ & $<0.001$ & 116.7 \\
\hline CSU & Itching $\rightarrow$ anxiety & Sleep quality & 0.084 & $<0.001$ & 0.011 & 0.546 & $0.073(-0.116,0.262)$ & $<0.001$ & 86.9 \\
\hline CSU & Itching $\rightarrow$ depression & Sleep quality & 0.084 & $<0.001$ & 0.017 & 0.359 & $0.068(-0.115,0.251)$ & $<0.001$ & 81.0 \\
\hline
\end{tabular}

CSU, chronic spontaneous urticaria.

${ }^{a}$ Total effect refers to the effect of predictor $(X)$ on outcome $(Y)$, adjusted from confounders but not mediators $(M)$.

${ }^{b}$ Direct effect refers to the effect of predictor $(X)$ on outcome $(Y)$, adjusted for confounders and mediators $(M)$.

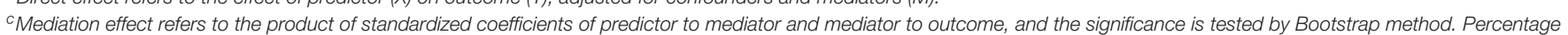
of mediation effect is calculated as: mediation effect/total effect $\times 100 \%$.

${ }^{d}$ Expressed as standardized regression coefficient.

through mediators including the symptoms of itching and sleep disturbance. We combined the known evidences from literatures and validated the hypothesis in adolescents. Our research suggests that effectively reducing the symptoms of itching thereby could increase natural sleep, which can reduce emotional problems among CSU patients.

\section{DATA AVAILABILITY STATEMENT}

The raw data supporting the conclusions of this article will be made available by the authors, without undue reservation.

\section{ETHICS STATEMENT}

This study was conducted according to the guidelines laid down in the Declaration of Helsinki. All procedures involving patients were approved by the institutional research ethics boards of Xiangya Hospital, Central South University (Changsha, China). Informed consent was obtained from all students before the investigation.

\section{AUTHOR CONTRIBUTIONS}

$\mathrm{YH}, \mathrm{YX}$, and DJ performed the dermatological examinations. Senior dermatologists JZ and JL were responsible for quality

\section{REFERENCES}

1. Zuberbier T, Aberer W, Asero R, Abdul Latiff AH, Baker D, Ballmer-Weber $\mathrm{B}$, et al. The EAACI/GA(2)LEN/EDF/WAO guideline for the definition, classification, diagnosis and management of urticaria. Allergy. (2018) 73:1393414. doi: 10.1111/all.13397 control for diagnoses. MS and $\mathrm{YH}$ analyzed the data and drafted the manuscript. MS and YX designed the questionnaire. MS, JL, $\mathrm{JZ}$, and $\mathrm{XC}$ designed the study and critically reviewed and revised the manuscript. MS and XC obtained the funding. All authors participated in the field survey and data collection and gave final approval to the version submitted for publication.

\section{FUNDING}

This work was supported by the Ministry of Science and Technology of People's Republic of China (grant\# 2016YFC0900802), Central South University (grant\# 202045005), and the Program of Introducing Talents of Discipline to Universities (111 Project, No. B20017).

\section{ACKNOWLEDGMENTS}

The authors would thank the following investigators that participated in the field survey (in order of family name): Lei Cai, Duling Cao, Qin Cao, Chao Chen, Menglin Chen, Jia Guo, Yeye Guo, Rui Hu, Xin Hu, Kai Huang, Xinwei Kuang, Li Lei, Keke Li, Yayun Li, Dihui Liu, Nian Liu, Panoan Liu, Runqiu Liu, Manyun Mao, Qunshi Qin, Lirong Tan, Ling Tang, Ni Tang, Tianhao Wu, Yun Xie, Lin Ye, Yi Yu, Hu Yuan, Rui Zhai, Zhibao Zhang, Yaqian Zhao, and Youyou Zhou. The diagnosis and management of acute and chronic urticaria: 2014 update. J Allergy Clin Immunol. (2014) 133:1270-7. doi: 10.1016/j.jaci.2014. 02.036

3. Magerl M, Altrichter S, Borzova E, Gimenez-Arnau A, Grattan CE, Lawlor F, et al. The definition, diagnostic testing, and management of chronic inducible 
urticarias - the EAACI/GA(2) LEN/EDF/UNEV consensus recommendations 2016 update and revision. Allergy. (2016) 71:780-802. doi: 10.1111/all.12884

4. Viegas LP, Ferreira MB, Kaplan AP. The maddening itch: an approach to chronic urticaria. J Investig Allergol Clin Immunol. (2014) 24:1-5.

5. Maurer M, Magerl M, Metz M, Zuberbier T. Revisions to the international guidelines on the diagnosis and therapy of chronic urticaria. J German Soc Dermatol. (2013) 11:971-7; quiz: 978. doi: 10.1111/ddg.12194

6. Kaplan AP. Clinical practice. Chronic urticaria and angioedema. N Engl J Med. (2002) 346:175-9. doi: 10.1056/NEJMcp011186

7. Karimkhani C, Dellavalle RP, Coffeng LE, Flohr C, Hay RJ, Langan SM, et al. Global skin disease morbidity and mortality: an update from the global burden of disease study 2013. JAMA Dermatol. (2017) 153:40612. doi: 10.1001/jamadermatol.2016.5538

8. Hashiro M, Okumura M. Anxiety, depression, psychosomatic symptoms and autonomic nervous function in patients with chronic urticaria. J Dermatol Sci. (1994) 8:129-35. doi: 10.1016/0923-1811(94)90007-8

9. Zuberbier T, Bindslev-Jensen C, Canonica W, Grattan CE, Greaves MW, Henz BM, et al. EAACI/GA2LEN/EDF guideline: definition, classification and diagnosis of urticaria. Allergy. (2006) 61:316-20. doi: 10.1111/j.1398-9995.2005.00964.x

10. Staubach P, Eckhardt-Henn A, Dechene M, Vonend A, Metz M, Magerl $\mathrm{M}$, et al. Quality of life in patients with chronic urticaria is differentially impaired and determined by psychiatric comorbidity. Br J Dermatol. (2006) 154:294-8. doi: 10.1111/j.1365-2133.2005.06976.x

11. Ben-Shoshan M, Blinderman I, Raz A. Psychosocial factors and chronic spontaneous urticaria: a systematic review. Allergy. (2013) 68:131-41. doi: 10.1111/all.12068

12. Huang Y, Xiao Y, Zhang X, Li J, Chen X, Shen M. A meta-analysis of observational studies on the association of chronic urticaria with symptoms of depression and anxiety. Front Med. (2020) 7:39. doi: 10.3389/fmed.2020.00039

13. Raap U, Kapp A, Wedi B, Stander S. Pruritus and urticaria. Hautarzt. (2010) 61:737-42. doi: 10.1007/s00105-010-1931-x

14. Yosipovitch G, Ansari N, Goon A, Chan YH, Goh CL. Clinical characteristics of pruritus in chronic idiopathic urticaria. Br J Dermatol. (2002) 147:326. doi: 10.1046/j.1365-2133.2002.04758.x

15. Bender BG, Ballard R, Canono B, Murphy JR, Leung DY. Disease severity, scratching, and sleep quality in patients with atopic dermatitis. J Am Acad Dermatol. (2008) 58:415-20. doi: 10.1016/j.jaad.2007.10.010

16. Zachariae R, Lei U, Haedersdal M, Zachariae C. Itch severity and quality of life in patients with pruritus: preliminary validity of a Danish adaptation of the itch severity scale. Acta Derm Venereol. (2012) 92:50814. doi: 10.2340/00015555-1221

17. Ferm I, Sterner M, Wallengren J. Somatic and psychiatric comorbidity in patients with chronic pruritus. Acta Derm Venereol. (2010) 90:395400. doi: 10.2340/00015555-0864

18. Halvorsen JA, Dalgard F, Thoresen M, Bjertness E, Lien L. Itch and pain in adolescents are associated with suicidal ideation: a population-based cross-sectional study. Acta Derm Venereol. (2012) 92:543-6. doi: 10.2340/00015555-1251

19. Matterne U, Apfelbacher CJ, Vogelgsang L, Loerbroks A, Weisshaar E. Incidence and determinants of chronic pruritus: a population-based cohort study. Acta Derm Venereol. (2013) 93:532-7. doi: 10.2340/00015555-1572

20. Schneider G, Driesch G, Heuft G, Evers S, Luger TA, Stander S. Psychosomatic cofactors and psychiatric comorbidity in patients with chronic itch. Clin Exp Dermatol. (2006) 31:762-7. doi: 10.1111/j.1365-2230.2006.02211.x

21. Silverberg JI, Hinami K, Trick WE, Cella D. Itch in the general internal medicine setting: a cross-sectional study of prevalence and quality-of-life effects. Am J Clin Dermatol. (2016) 17:68190. doi: 10.1007/s40257-016-0215-3

22. Baglioni C, Battagliese G, Feige B, Spiegelhalder K, Nissen C, Voderholzer $\mathrm{U}$, et al. Insomnia as a predictor of depression: a meta-analytic evaluation of longitudinal epidemiological studies. J Affect Disord. (2011) 135:109. doi: 10.1016/j.jad.2011.01.011

23. Huang X, Zhang J, Li J, Zhao S, Xiao Y, Huang Y, et al. Daily intake of soft drinks and moderate-to-severe acne vulgaris in chinese adolescents. J Pediatr. (2019) 204:256-62.e3. doi: 10.1016/j.jpeds.2018.08.034

24. Zuberbier T, Aberer W, Asero R, Bindslev-Jensen C, Brzoza Z, Canonica $\mathrm{GW}$, et al. Methods report on the development of the 2013 revision and update of the EAACI/GA2 LEN/EDF/WAO guideline for the definition, classification, diagnosis, and management of urticaria. Allergy. (2014) 69:e129. doi: $10.1111 /$ all.12313

25. Medansky RS, Handler RM. Dermatopsychosomatics: classification, physiology, and therapeutic approaches. J Am Acad Dermatol. (1981) 5:125-36. doi: 10.1016/S0190-9622(81)70081-1

26. Koo JY, Pham CT. Psychodermatology. Practical guidelines on pharmacotherapy. Arch Dermatol. (1992) 128:3818. doi: 10.1001/archderm.128.3.381

27. Koblenzer CS. Psychosomatic concepts in dermatology. A dermatologist-psychoanalyst's viewpoint. Arch Dermatol. (1983) 119:501-12. doi: 10.1001/archderm.119.6.501

28. Panconesi E. Psychosomatic dermatology. Clin Dermatol. (1984) 2:94179. doi: 10.1016/0738-081X(84)90050-6

29. Gupta MA, Gupta AK. The use of psychotropic drugs in dermatology. Dermatol Clin. (2000) 18:711-25, x. doi: 10.1016/S0733-8635(05)70222-9

30. Dauden E, Castaneda S, Suarez C, Garcia-Campayo J, Blasco AJ, Aguilar MD, et al. Clinical practice guideline for an integrated approach to comorbidity in patients with psoriasis. J Euro Acad Dermatol Venereol. (2013) 27:1387404. doi: 10.1111/jdv.12024

31. Thyssen JP, Hamann CR, Linneberg A, Dantoft TM, Skov L, Gislason GH, et al. Atopic dermatitis is associated with anxiety, depression, and suicidal ideation, but not with psychiatric hospitalization or suicide. Allergy. (2018) 73:214-20. doi: 10.1111/all.13231

32. Chung MC, Symons C, Gilliam J, Kaminski ER. Stress, psychiatric comorbidity and coping in patients with chronic idiopathic urticaria. Psychol Health. (2010) 25:477-90. doi: 10.1080/08870440802530780

33. Weisshaar E, Szepietowski JC, Dalgard FJ, Garcovich S, Gieler U, GimenezArnau AM, et al. European S2k guideline on chronic pruritus. Acta Derm Venereol. (2019) 99:469-506. doi: 10.2340/00015555-3164

34. Gaig P, Olona M, Munoz Lejarazu D, Caballero MT, Dominguez FJ, Echechipia S, et al. Epidemiology of urticaria in Spain. J Investig Allergol Clin Immunol. (2004) 14:214-20.

35. Dalgard FJ, Svensson A, Halvorsen JA, Gieler U, Schut C, Tomas-Aragones $\mathrm{L}$, et al. Itch and mental health in dermatological patients across Europe: a cross-sectional study in 13 countries. J Investig Dermatol. (2020) 140:56873. doi: 10.1016/j.jid.2019.05.034

36. Stumpf A, Schneider G, Stander S. Psychosomatic and psychiatric disorders and psychologic factors in pruritus. Clin Dermatol. (2018) 36:7048. doi: 10.1016/j.clindermatol.2018.08.015

37. Yosipovitch G, Ishiuji Y, Patel TS, Hicks MI, Oshiro Y, Kraft RA, et al The brain processing of scratching. I Investig Dermatol. (2008) 128:180611. doi: $10.1038 /$ jid.2008.3

38. Zhao X, Yu C, Ye F, Wang YG, Mei QY, Ma Q, et al. Chronic itch impairs mood and HPA axis function in mice: modulation by CRFR1 antagonist. Pain. (2018) 159:2201-13. doi: 10.1097/j.pain.0000000000001319

39. O’Donnell BF, Lawlor F, Simpson J, Morgan M, Greaves MW. The impact of chronic urticaria on the quality of life. Br J Dermatol. (1997) 136:197201. doi: 10.1111/j.1365-2133.1997.tb14895.x

40. O'Donnell BF. Urticaria: impact on quality of life and economic cost. Immunol Allergy Clin North Am. (2014) 34:89-104. doi: 10.1016/j.iac.2013.09.011

41. Mlynek A, Magerl M, Hanna M, Lhachimi S, Baiardini I, Canonica GW, et al. The German version of the Chronic Urticaria Quality-of-Life Questionnaire: factor analysis, validation, and initial clinical findings. Allergy. (2009) 64:92736. doi: 10.1111/j.1398-9995.2008.01920.x

42. Livingston G, Blizard B, Mann A. Does sleep disturbance predict depression in elderly people? A study in inner London. Br J General Prac. (1993) 43:445-8.

43. Roberts RE, Shema SJ, Kaplan GA, Strawbridge WJ. Sleep complaints and depression in an aging cohort: a prospective perspective. Am J Psychiatry. (2000) 157:81-8. doi: 10.1176/ajp.157.1.81

44. Franzen PL, Buysse DJ. Sleep disturbances and depression: risk relationships for subsequent depression and therapeutic implications. Dial Clin Neurosci. (2008) 10:473-81. doi: 10.31887/DCNS.2008.10.4/plfranzen

45. Alapin I, Libman E, Bailes S, Fichten CS. Role of nocturnal cognitive arousal in the complaint of insomnia among older adults. Behavioral sleep medicine. (2003) 1:155-70. doi: 10.1207/S15402010BSM0103_3

46. Almeida OP, Pfaff JJ. Sleep complaints among older general practice patients: association with depression. Br J General Pract. (2005) 55:864-6.

47. Short MA, Booth SA, Omar O, Ostlundh L, Arora T. The relationship between sleep duration and mood in adolescents: a systematic review and 
meta-analysis. Sleep Med Rev. (2020) 52:101311. doi: 10.1016/j.smrv.2020. 101311

48. Cox RC, Olatunji BO. Sleep in the anxiety-related disorders: a metaanalysis of subjective and objective research. Sleep Med Rev. (2020) 51:101282. doi: 10.1016/j.smrv.2020.101282

49. Ozdemir P, Karadag A, Selvi Y, Boysan M, Bilgili S, Aydin A, Onder SJIjopicp. Assessment of the effects of antihistamine drugs on mood, sleep quality, sleepiness, and dream anxiety. Int J Psychiatry Clin Pract. (2014) 18:1618. doi: 10.3109/13651501.2014.907919

Conflict of Interest: The authors declare that the research was conducted in the absence of any commercial or financial relationships that could be construed as a potential conflict of interest.
Publisher's Note: All claims expressed in this article are solely those of the authors and do not necessarily represent those of their affiliated organizations, or those of the publisher, the editors and the reviewers. Any product that may be evaluated in this article, or claim that may be made by its manufacturer, is not guaranteed or endorsed by the publisher.

Copyright (c) 2021 Huang, Xiao, Jing, Li, Zhang, Chen and Shen. This is an openaccess article distributed under the terms of the Creative Commons Attribution License (CC BY). The use, distribution or reproduction in other forums is permitted, provided the original author(s) and the copyright owner(s) are credited and that the original publication in this journal is cited, in accordance with accepted academic practice. No use, distribution or reproduction is permitted which does not comply with these terms. 